\section{Multiple Regression Models for the Analysis of Potential Cultivation Areas for Japanese Plums}

\author{
Agustín Rumayor-Rodríguez \\ Instituto Nacional de Investigaciones Forestales y Agropecuarias, Campo \\ Experimental Calera, Apartado Postal 18 Calera, Zacatecas 98500, México
}

Additional index words. Prunus salicina, cultivars, temperatures, potential production areas, fruit yields

\begin{abstract}
The annual yield variation in a Japanese plum (Prunus salicina Lindl.) germplasm collection [with 32 cultivars (cv)] was used to generate regression models to describe fruit yields in terms of climate. A Geographic Information System (GIS) combined with generated regression models was used for a regional analysis of potential areas for growing plums in Zacatecas, Mexico. Three distinct cv groups were obtained by principal component analysis and were included in the study: a) 'Frontier'-'Santa Rosa', b) 'Ozark Premier'-'Burbank', and c) 'Shiro'. The amount of winter chilling and temperatures during bloom time were the climatic conditions most related to yield. 'Frontier'-'Santa Rosa' had relatively low chilling requirements ( 700 chill units) compared to 'Ozark Premier'-'Burbank', which required the most chilling (900 chill units). 'Shiro' yields were more consistent than those of the other two groups, suggesting that it has less strict requirements and received sufficient chilling every year. High temperatures at bloom reduced fruit yield in all cultivars; however, the dependence of yield on temperatures during bloom in 'Shiro' was modified by summer temperatures the previous year, suggesting that temperatures at the floral induction and formation stages affect flower primordia development. Using GIS, three potential areas for growing plums in the region were defined on maps, and the differences in potential yield between the cultivar groups were determined. 'Frontier'-'Santa Rosa' may be good choices as plum cultivars for the region because they were the cultivars with the highest potential yield in the largest area; however, the flexibility of the method used allows the user to get a regional gradient of the expected yields with several plum cultivars. Using experimental information and a GIS can extend the applicability of germplasm collection data to regional planning in the establishment of orchards and new fruit industries.
\end{abstract}

Temperate fruit production in Mexico is based mainly on grape (Vitis vinifera L.), apple (Malus domestica Borkh.), peach [Prunus persica (L.) Batsch.], pecan [Carya illinoiensis (Wang.) K. Koch.], pear (Pyrus communis L.), and plum (Prunus salicina Lindl., $P$. domestica L.) (Diaz et al., 1986). Zacatecas state is located in north-central Mexico, and its fruit industry includes mainly peaches $(25,000 \mathrm{ha})$; however, there is potential for other temperate fruit crops that can be used to diversify fruit production. Japanese plum (Prunus salicina Lindl.) is native to China and was introduced to California in 1870 (La Rue and Gerdts, 1976). Mexico grows 5000 ha of plums. The major Japanesetype ( $P$. salicina and hybrids) cultivars are 'Santa Rosa', 'Methley', 'Frontier', and some local seedlings.

Germplasm collections of fruit trees and their characterization are useful to detect genotypes adapted to local conditions. However, annual variation in yield and bloom dates are frequently observed in these orchards. This

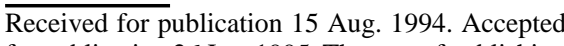
for publication 26 Jan. 1995. The cost of publishing this paper was defrayed in part by the payment of page charges. Under postal regulations, this paper therefore must be hereby marked advertisement solely to indicate this fact. annual variation is particularly important in regions with wide fluctuations in daily and annual conditions (del Real-Laborde, 1987). Plum yield instability has been reported. For example, 'Brooks' has a more consistent annual production than 'Italian' (Moreno et al., 1992). Yields varied significantly among years in a Japanese plum germplasm collection in Zacatecas without any apparent cause, such as frost damage, alternate bearing, or tree age (Rumayor-Rodríguez et al., 1991).

Several climatic conditions may affect annual yields of deciduous fruit trees and account for their fluctuations. Winter chilling requirements of most Japanese plums are 700 to $1000 \mathrm{~h}$ (La Rue and Gerdts, 1976); when these requirements are not satisfied, lack of chilling is associated with erratic budbreak, delayed bloom, abnormal flowers, and poor fruit set (Erez, 1987). After completion of winter chilling, fruit trees require warm spring weather, defined as growing degree hours, to initiate budbreak (Richardson et al., 1975). Temperatures during and after full bloom also may affect yield by reducing fruit set of deciduous fruit trees. The effects of temperatures on pollination (Williams, 1970), pollen tube growth (Keulemans, 1984), ovule longevity (Moreno et al., 1992), and stigma receptivity (Pimienta et al., 1983) have been reported.

Flower primordia of fruit trees originate the previous summer. Bud initiation is influenced by environmental factors, such as temperature, light, and daylength (Jackson and Sweet, 1972). Flower bud initiation of plums in Mexico was reported in May and June for early ('Methley') and late ('Shiro') blooming cultivars, respectively (Avitia and Castillo, 1991).

Multivariate analysis has been used to describe associations between variables, taking advantage of the variables' linear relationships (Iezzoni and Pritts, 1991). For example, in germplasm collections, these analyses were used to group genotypes within a collection by characteristics of the genotypes (Hilling and Iezzoni, 1988; Perez-Gonzalez, 1992).

Crop simulation models can predict crop yield, plant growth, and development, and nutrient and moisture dynamics based on sitespecific characteristics, such as weather, soil, and agronomic practices (Whistler et al., 1986). Recently, Lal et al. (1993) extended the applicability of site-specific models for beans (Phaseolus vulgaris L.) to regional productivity analysis by combining their capabilities with a Geographic Information System (GIS). A GIS is a database management system for map-oriented data. For any region, a set of maps can be added to the database as digitized images to represent different data themes describing the region. Within each data theme, regions of homology are identified and attributes describing those regions are stored in tables that can reference a map. Several computer softwares are available for data acquisition, input, storage, management, analysis, modeling, and presentation.

This study was motivated by the following aims: 1) to obtain groups of Japanese plum cultivars that, based on their productivity and blooming characteristics, had similar behavior during an experimental period; 2) to develop mathematical models, using the climatic conditions, to explain year-to-year variations of yields in the selected plum cultivars; and 3) to use a GIS and the models obtained to perform a regional productivity analysis for plums and to find feasible areas for their cultivation in Zacatecas, Mexico.

\section{Materials and Methods}

Location characteristics. Data from a germplasm collection of 32 Japanese plum cultivars were used. The orchard was established at Campo Experimental Calera,Zacatecas, which is a research station of the Instituto Nacional de Investigaciones Forestales y Agropecuarias (INIFAP) of the Mexican Secretary of Agriculture.

The experimental site is located at lat. $22^{\circ} 54^{\prime} \mathrm{N}$ and long. $102^{\circ} 39^{\prime} \mathrm{W}$. It is $2197 \mathrm{~m}$ above sea level and has an annual mean of 14.2C with mean 9.7C in January and 18.0C in June. Average chilling accumulation from November to February, calculated as chill units (Richardson et al., 1974), is 634; however, fluctuations from 250 to 1000 units occur in "warm" and "cold" winters, respectively. Average annual rainfall (60\% probability) is 383 $\mathrm{mm}$, with $75 \%$ of this rain in summer, particu- 
larly in August and September, and average pan evaporation at $2216 \mathrm{~mm}$. The largest differences between rainfall and evaporation ( 150 mm per month) are found in March, April, and May during and after blooming of most plum cultivars. These rainfall and evaporation characteristics indicate that irrigation is needed to grow plums in this region.

Orchard characteristics. In 1972, plum trees were planted randomly at $6 \times 6 \mathrm{~m}$ on Marianna 2624 rootstock and were cultivated thereafter following standard cultural practices (La Rue and Gerdts, 1976). The 12 most productive cultivars of the collection were selected for the study: 'Burmosa', 'Bruce', 'Burbank', 'Casselman', 'El Dorado', 'Frontier', 'Laroda', 'Nubiana', 'Ozark Premier', 'Red Heart', 'Santa Rosa', and 'Shiro'. The analysis included 8 productive years (from 1978 to 1985) in which the following variables were evaluated: yield per tree (y), bloom (beginning, full, and end) dates (bl), number of open buds in spring (nb), and number of fruit set (nf) per $0.20 \mathrm{~m}$ of shoot length. Yield per tree was obtained by weighing the total amount of fruit at harvest (June and July). Full bloom was considered when $80 \%$ of the buds were open. The numbers of buds and fruit were estimated by considering counts of five shoots in a $0.20-\mathrm{m}$ length at random. Nine trees per cultivar were considered as replications.

Temperature-related records. Weather data for each of the annual harvests were included to describe temperature conditions in the previous winter, at bloom, and during the period when floral induction and development occurred (i.e., during the summer of the year that preceded the current year's harvest). Temperature-related variables calculated were chill units (Richardson et al., 1974) during November (Ncu), December (Dcu), January (Jcu), and February (Fcu); number of hours at $<7.2 \mathrm{C}$ in November (Nch), December (Dch), January (Jch), and February (Fch); number of hours with temperatures $>18 \mathrm{C}$ during November (Nht), December (Dht), January (Jht), and February (Fht); growing degree hours (base temperature $5 \mathrm{C}$ ) during bloom (gdhb); number of hours with temperatures $>16 \mathrm{C}\left(\mathrm{nh}^{16+}\right)$, $>21 \mathrm{C}\left(\mathrm{nh}^{21+}\right)$, or $<10 \mathrm{C}\left(\mathrm{nh}^{10-}\right)$ during bloom; and growing degree hours (base temperature 5C) during the flower formation period [May (gdhM), June (gdhJe), July (gdhJy), and August (gdhA) the year before the year of harvest]. Rainfall data were not included because the experimental orchard was irrigated, with all cultivars receiving similar amounts of water. Moreover, the late summer occurrence of most rains does not represent any major disease problems for Japanese plums in the region.

Datahandling. Statistical analyses included principal component (PC), cluster, and regression analysis. To perform $\mathrm{PC}$ analysis, all data sets were standardized to zero mean and unit variance (Iezzoni and Pritts, 1991); therefore, PC scores are presented as standardized values. PCs, with the descriptive data of plum cultivars, were generated to group similar genotypes (Iezzoni and Pritts, 1991). Due to the linear relations between weather data, PC analysis also was performed to calculate independent climatological variables, referred to as "climatic indexes." After completion of the PC analysis, second-order polynomial equations were fitted to the yield data using linear, quadratic, and cross-product terms of climatic indexes or PCs. The regression model used was in the following form: $Y=\beta_{0}+b_{1} X_{1}+$ $\beta_{11} X^{2}{ }_{1}+\beta_{2} X_{2}+\beta_{22} X^{2}{ }_{2}+\beta_{12} X_{1} X_{2}+\beta_{1122} X_{1}{ }^{2} X_{2}{ }^{2}$, where $\mathrm{Y}=$ yield; $\mathrm{X}_{1}=$ climatic index or PC1 (for example, winter chilling); and $\mathrm{X}_{2}=$ climatic index or PC2. Components were deleted from the model if their parameter estimate $(\beta)$ was not significant $(P \leq 0.05)$ or if its deletion did not decrease the $R^{2}$ of the model. These equations allowed response surfaces to be generated for fruit yield of plums to climate, which are presented as graphs of the predicted values. All analyses were performed with the

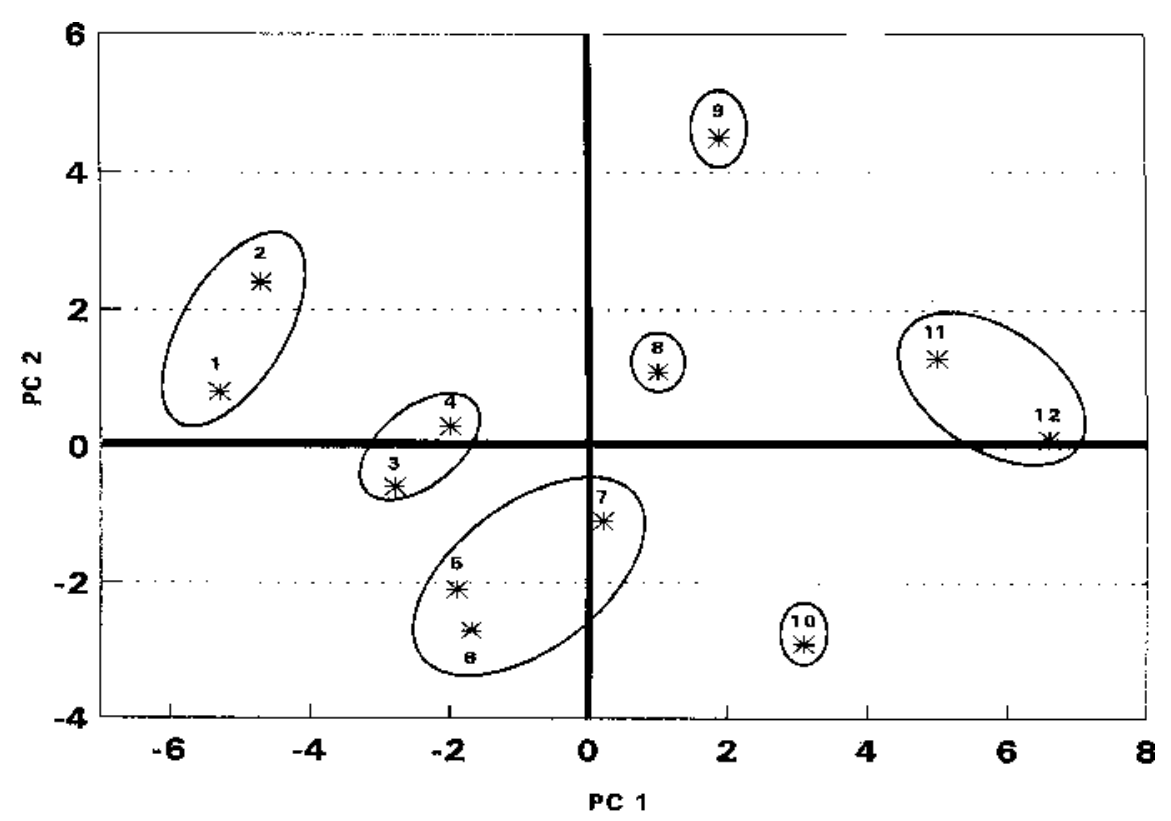

Fig. 1. Grouping of Japanese plum cultivars according to their bloom characteristics (PC1) and yield (PC2). Principal component scores are presented as standardized values. Cultivars were: $1=$ 'Frontier', $2=$ 'Santa Rosa', 3 = 'Laroda', 4 = 'Nubiana', 5 = 'Red Heart', $6=$ 'El Dorado', 7 = 'Casselman', 8 = 'Bruce', $9=$ 'Shiro', $10=$ 'Burmosa', $11=$ 'Burbank', and $12=$ 'Ozark Premier'.

Table 1. Eigen value, total variation, cumulative variation, and the original variables included into each principal component (PC) generated for the climatic conditions related to fruit yield of five cultivars of Japanese plums.

\begin{tabular}{|c|c|c|c|c|}
\hline $\mathrm{PC}$ & $\begin{array}{l}\text { Eigen } \\
\text { value }\end{array}$ & $\begin{array}{c}\text { Total } \\
\text { variation } \\
(\%)\end{array}$ & $\begin{array}{c}\text { Cumulative } \\
\text { variation } \\
(\%)\end{array}$ & Original variables ${ }^{\mathrm{z}, \mathrm{y}}$ \\
\hline Winter chilling (PC1) & 9.04 & 43 & 43 & $\begin{array}{c}\text { Nch }(0.61), \text { Dch }(0.70), \\
\text { Jch }(0.87), \text { Fch }(0.96), \\
\text { Ncu }(0.94) \text {, Dcu }(0.77), \\
\text { Nht }(-0.64) \text {, Dht }(-0.69), \\
\text { Jht }(-0.76) \text {, Fht }(-0.85)\end{array}$ \\
\hline $\begin{array}{l}\text { Temperatures } \\
\text { during bloom (PC2) }\end{array}$ & 3.78 & 18 & 61 & $\begin{array}{l}\operatorname{gdhb}(0.78), \mathrm{nh}^{16+}(0.66), \\
\mathrm{nh}^{21+}(0.59)\end{array}$ \\
\hline
\end{tabular}

Chilling in

\begin{tabular}{|c|c|c|c|c|}
\hline February (PC3) & 2.55 & 14 & 75 & Fcu (0.60) \\
\hline temperatures (PC4) & 1.88 & 8 & 83 & $\begin{array}{l}\text { gdhJe (0.60), gdhJy (0.54), } \\
\operatorname{gdhA}(0.48)\end{array}$ \\
\hline
\end{tabular}

Chilling in

$\begin{array}{lllll}\text { January (PC5) } & 1.61 & 7 & 95 & \text { Jcu (0.59) }\end{array}$

${ }^{2}$ Number in parentheses indicates the correlation coefficient for the original variable and the PC value. ${ }^{y}$ Abbreviation of variable names are given in text. 
daily mean maximum, daily mean minimum, and daily mean temperatures for each month. Soil maps (scale 1:1,000,000) were digitized into GIS using the software ARC/INFO v 3.4

(Environmental Research Systems, Redlands, Calif.); this scale was considered to be adequate because this database was used only to include deep soils (>100 cm depth), without

Table 2. Regression equations, degrees of freedom, mean square, coefficients of determination $\left(R^{2}\right)$, and calculated $\mathrm{F}$ value $(\mathrm{Fc})$ of the response surfaces generated for yields of three groups of Japanese plums in response to temperatures at bloom $\left(\mathrm{X}_{1}\right)$, winter chilling $\left(\mathrm{X}_{2}\right)$, and in the previous summer $\left(\mathrm{X}_{3}\right)$.

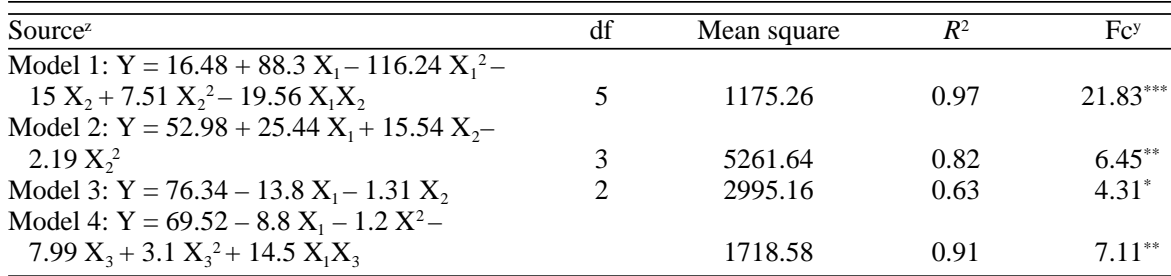

${ }^{2}$ Models used in Figs. 2 and 3 to generate response surfaces. Model 1: 'Frontier'-'Santa Rosa'; Model 2: 'Ozark Premier'-'Burbank'; Model 3 and 4: 'Shiro'.

*,**,****F value significant at $P \leq 0.10,0.05$, or 0.01 , respectively.

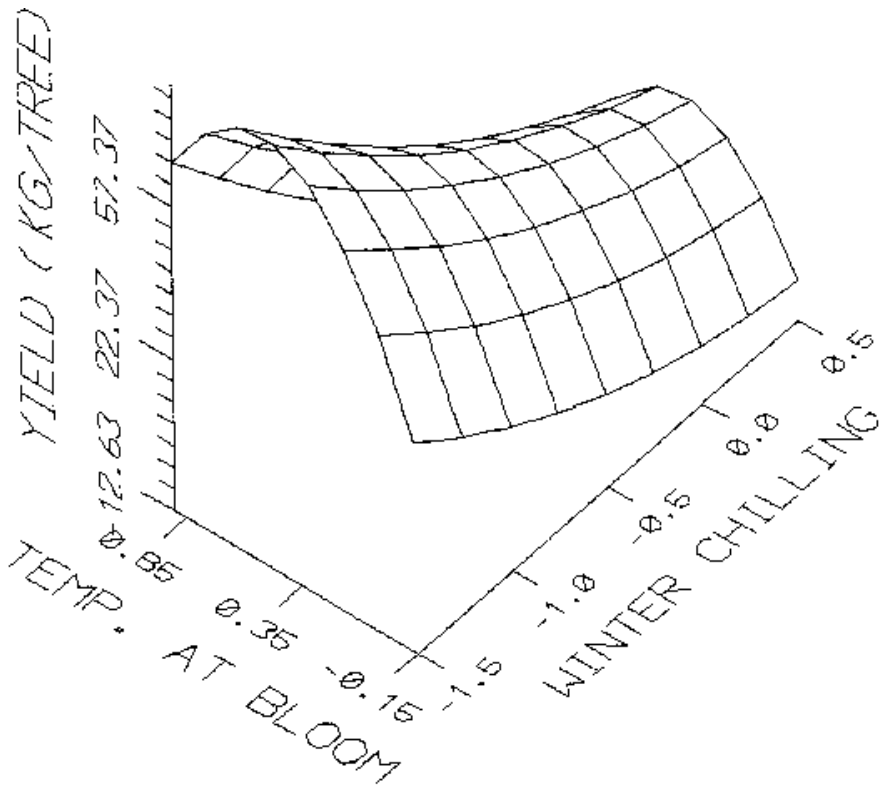

A

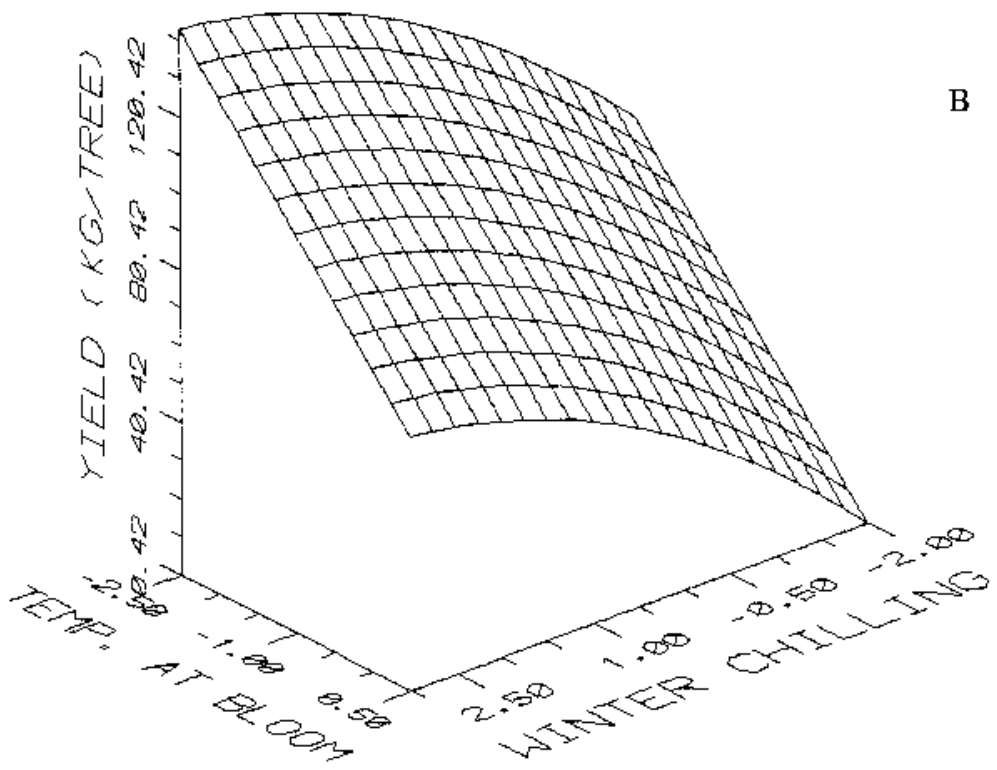

Fig. 2. Response surfaces of predicted yields for (A) 'Frontier'-'Santa Rosa' and (B) 'Ozark Premier''Burbank', derived from equations in Table 2, as influenced by temperatures at bloom and winter chilling. Variable axes represent standardized principal component scores. other limitations (such as salinity), and excluding mountains, water reservoirs, and inhabited areas from the productivity analysis. A more precise study, such as the effects of soil types on tree growth and yield, would require a more detailed soil map to be digitized.

\section{Results and Discussion}

I divided the results into four sections: cultivar grouping, PC analysis on temperature-related variables, regression models describing potential yield, and potential yield maps.

Cultivar grouping. The descriptive variables of trees throughout the eight experimental years were integrated by PC analysis and were used for grouping similar cultivars. Two PCs (PC1 and PC2) were generated (Iezzoni and Pritts, 1991): PC1 represented bloom characteristics of cultivars in the experimental period and included the variables bl and $\mathrm{nb}$, and PC2 involved fruit yield with the variables $\mathrm{y}$ and $\mathrm{nf}$. Using the $\mathrm{PC}$ scores obtained for each cultivar, seven groups of cultivars with similar bloom characteristics and potential yield were formed (Fig. 1). Four groups of plum cultivars included at least two genotypes. The three one-element groups, including 'Bruce', 'Shiro', and 'Burmosa', were considered atypical and not related to any other genotype.

According to the fruit characteristics of each genotype and its behavior in the experimental period, three groups were considered to be representative of the variation in bloom and yield characteristics. These three cultivar groups [a) 'Frontier'-'Santa Rosa', b) 'Ozark Premier'-'Burbank', and c) 'Shiro'] were used to determine the relationships between temperature and fruit yield of Japanese plums. 'Frontier' and 'Santa Rosa' were the earliestblooming cultivars and had a fruit yield near the overall mean. The second group was composed of 'Ozark Premier' and 'Burbank'; these were the latest-blooming cultivars and had a slightly higher yield than the general mean. Finally, 'Shiro' was considered as a group, although it was not related to any other cultivar because it was the most productive and consistent cultivar (Fig. 1).

$P C$ analysis on temperature-related variables. A preliminary correlation and multiple regression analysis between the temperaturerelated variables and fruit yields suggested that strong colinearity existed among the variables related to temperatures. Thus, $\mathrm{PC}$ analysis was performed to generate independent temperature variables (Iezzoni and Pritts, 1991), designated as climatic indexes. Then regression equations to explain annual variation of yields were calculated, including the PCs obtained or the climatic indexes as independent variables.

Table 1 includes eigen values, the proportion of the variability represented by the main PCs and the original variables best correlated with each PC. According to the interpretation of PC analysis (Iezzoni and Pritts, 1991), 83\% of the observed variability was explained by the first four PCs or $95 \%$ by the first five. 
These PCs were named according to the main variables included in each; the significance of the included variables was determined by examining their eigen value and correlation coefficients between the original values and the corresponding PC. Winter chilling was defined as PC1; PC2 was designated as temperatures during bloom; the amount of chilling in February was integrated into PC3; and PC4 included temperatures (growing degree hours) in summer of the year before the year of harvest. The relationships between the climatic variables in each PC were noted clearly. For example, the variables included in PC1 (winter chilling) were those describing low temperatures in the winter (chill units or hours) with a positive correlation and the negative effect on chilling accumulation of high temperatures $(>18 \mathrm{C})$ during the same period as the coefficients between PC values and the origi-
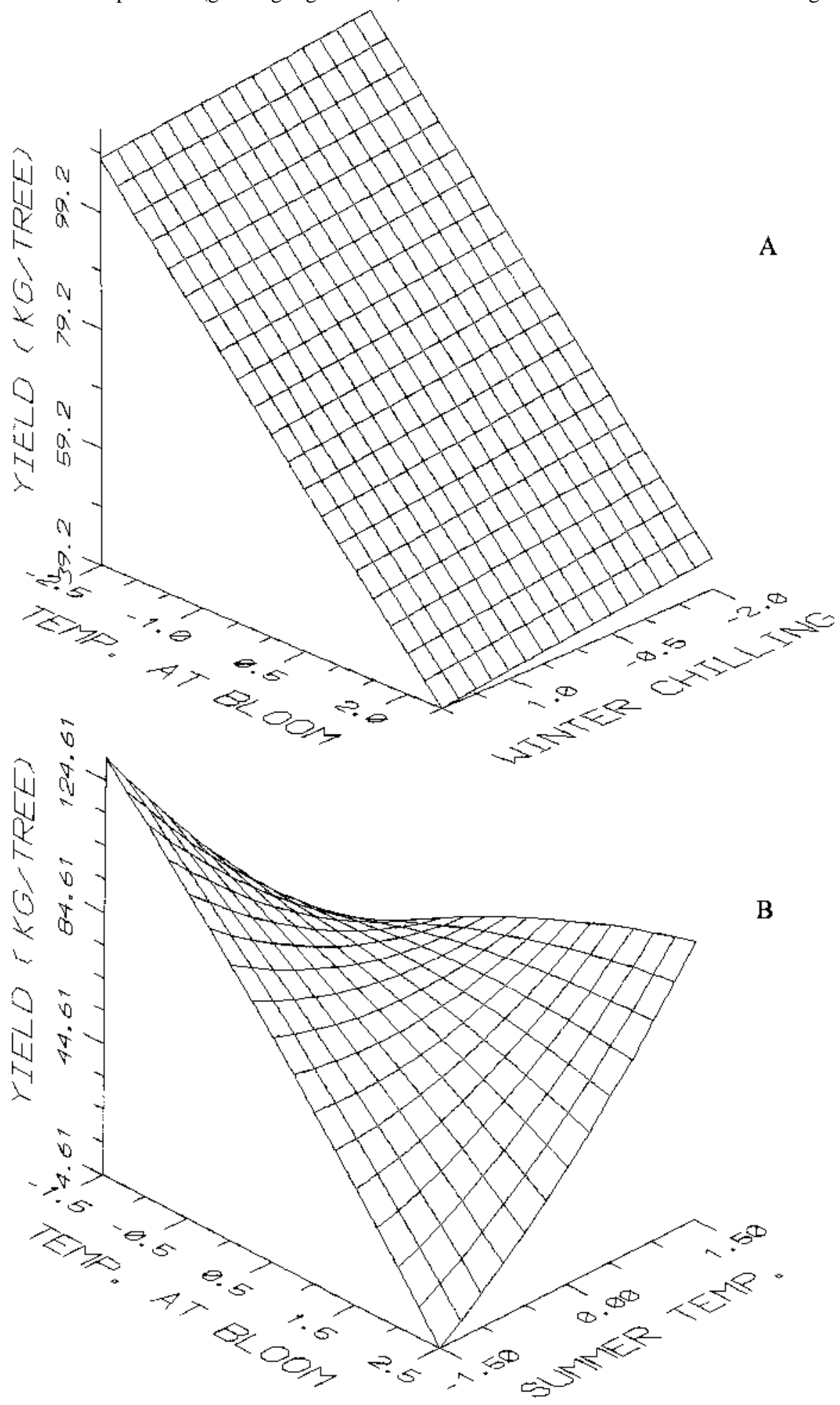

Fig. 3. Response surfaces of predicted yields for 'Shiro' derived from equations in Table 2. (A) Effects of temperatures at bloom and winter chilling and $(\mathbf{B})$ at bloom and summer temperatures. Variable axes represent standardized principal component scores.

nal variables indicated (Table 1). These relations suggest that in those years when temperatures during winter are above normal, a reduction in chilling accumulation is registered (del Real-Laborde, 1987). The relevance of using PC analysis was to reduce a large number of highly correlated temperature variables to five independent PCs to perform the response surface analysis, thus having a single PC value or score to describe temperaturerelated conditions of each year and harvest.

Regression equations describing potential yield. Full second-order polynomial equations were fit to the data, considering the generated climatic indexes and yield. The model best describing the relationship between yield and the climatic components for each group was selected, and response surfaces were generated. The models were capable of explaining between $63 \%$ and $97 \%$ of Japanese plum yield annual variation by fluctuations in temperatures (Table 2). Only three climatic indexes (PCs) were significantly $(P \leq 0.05)$ related to yields: winter chilling, temperatures during bloom, and summer temperatures. Among these, temperatures during bloom most affected yield of all cultivar groups.

Yield of 'Frontier'-'Santa Rosa' was related to winter chilling and temperatures during bloom (Fig. 2A). The response surface generated $\left(R^{2}=0.97\right)$ revealed a maximum yield of $60 \mathrm{~kg}$ per tree with a value for temperatures at bloom close to the mean ( $\mathrm{PC}=$ $0.4)$ and with relatively low winter chilling $(\mathrm{PC}=-1.50)$. In those years when temperatures during bloom were lower and higher than a PC value of 0.4 , yields were reduced, suggesting that it is an optimum temperature for fruit set. High temperatures reduce ovule longevity (Moreno et al., 1992) and low temperatures retard pollen tube growth (Williams, 1970); therefore, fruit set can be diminished by a failure in fertilization derived from inappropriate temperatures at bloom. This cultivar group had the lowest chilling requirement, 700 chill units (Richardson et al., 1974), which can be supported by the fact that these trees bloomed earlier than cultivars in the other groups (Fig. 1) and they did not show symptoms associated with lack of chilling in lowchilling years.

'Ozark Premier'-'Burbank' yields also were related to temperatures at bloom and winter chilling (Fig. 2B) $\left(R^{2}=0.82\right)$. The relationship between yield and temperatures at bloom was clearly linear, having the highest yields in those years when temperatures at bloom were relatively low $(\mathrm{PC}=-2.5)$. High temperatures at bloom clearly reduced potential yield. This finding agrees with that of Moreno et al. (1992), who found that increasing temperatures induced faster ovule senescence and consequently reduced fruit set. These two cultivars are considered to have a high chilling requirement because of their late bloom dates (Fig. 1) and the observed relationship between yield and winter chilling; the maxiyields were registered in those years of high winter chilling $(\mathrm{PC}=+2.50)$, and the yields were reduced as chilling decreased (Fig. 2B). The yield reduction in low chilling years 
agreed with the presence of symptoms of inadequate chilling, such as bud opening delay and bud abortion. 'Ozark Premier' and 'Burbank' require $\geq 900$ chill units (Richardson et al., 1974) (Fig. 2B) to produce consistently and are potential cultivars for Zacatecas, particularly because of their late bloom. However, the need for completion of the required winter chilling by these late-blooming cultivars has to be considered in selecting feasible orchard sites to avoid prolonged bloom periods and to reduce the possibility of having high temperatures at bloom.

'Shiro' was a consistent and productive cultivar. According to its yield relation with temperatures at bloom and winter chilling (Fig. 3A) $\left(R^{2}=0.63\right)$, it is a plum cultivar with less-strict chilling requirements than the other two groups. At least under our experimental conditions, 'Shiro' trees always received sufficient chilling and produced similarly in years with differing amounts of chilling accumulation. However, 'Shiro' also is a relatively lateblooming cultivar compared to 'Santa Rosa' and 'Frontier' (Fig. 1), which suggests that its bloom dates may be defined by its post-rest heat requirements and not by its chilling accumulation, as reported in other species (Werner et al., 1988). In contrast, the relationship between yield and temperatures at bloom for 'Shiro' was similar to that for 'Ozark Premier'-'Burbank', having a negative linear response and indicating that high temperatures $(\mathrm{PC}>+1)$ at bloom negatively affect fruit yield, as previously discussed.

Fruit yields for 'Shiro' also were related significantly $(P \leq 0.05)$ to temperatures during the previous summer and its interaction with temperatures at bloom (Fig. 3B) $\left(R^{2}=0.91\right)$. When temperatures from the previous summer were relatively high $(\mathrm{PC}>0.75)$, flowers that formed seemed to be less susceptible to high temperatures at bloom the following spring (Fig. 3B). Yields were clearly more consistent and not reduced at high bloom temperatures $(\mathrm{PC}=2.5)$ after the previous summer had relatively high $(\mathrm{PC}=1.5)$ temperatures (Fig. 3B). This finding corresponds to the strong flower in apples (Williams, 1965), indicating that strong flowers are formed with adequately high temperatures and weak blossoms are produced when summers are relatively cool. The normal, vigorous, strong flower may tolerate high temperatures at bloom better than weak floral tissue. Ovule longevity in plums is reduced by high temperatures, but there are differences between cultivars in ovule tolerance of high temperatures (Moreno et al., 1992), suggesting that a more consistent yield may be associated with a cultivar with strong blossoms, a cultivar in which ovule viability is less affected by high temperatures at bloom. Erez (1987) reported that lack of chilling produces weak flowers and reduces fruit set. However, more work is needed to clarify the relationship of temperatures at bloom and during fruit bud development with flower vigor and ovule senescence rates.

Potential yield maps. Three districts for potential plum cultivation were clearly distinguished (Fig. 4A): Rio Grande (area I),
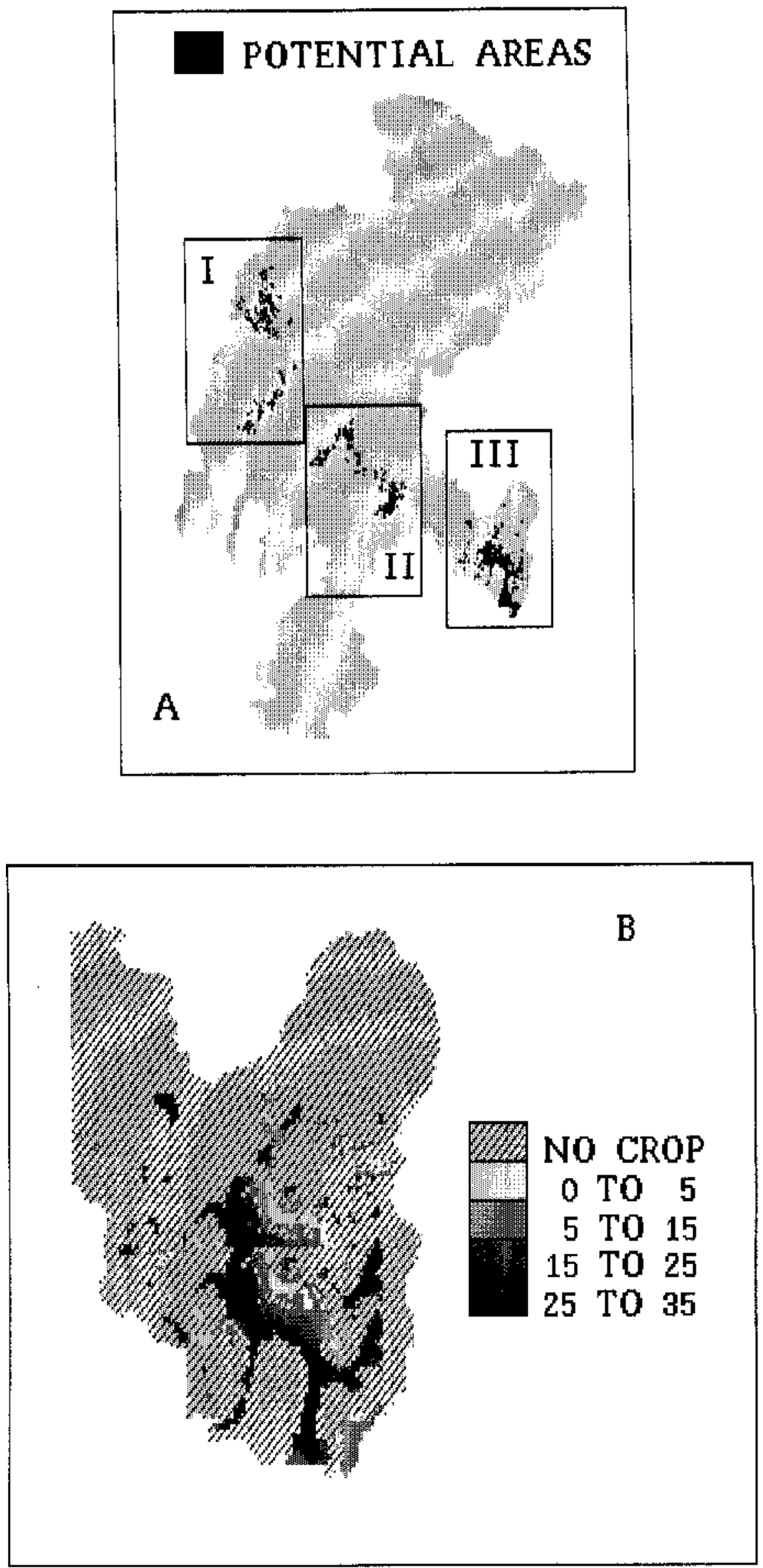

Fig. 4. Potential areas for cultivation of 'Frontier' and 'Santa Rosa' plums in (A) Zacatecas, Mexico, and their yield potential (tonnes per hectare) in (B) Ojocaliente District. 
Zacatecas (area II), and the Ojocaliente (area III). In the three districts, several fruit crops are cultivated currently, particularly peaches, grapes, apples, and a few hectares of Japanese plums ('Santa Rosa'). These three potential areas were chosen for all three cultivar groups, but their potential yield differed (Table 3), suggesting that there is a potential area for growing plums in general, but that the selection of well-adapted genetic material for each area is essential for the highest potential yield. More evidence for this requirement is given by a closer look at the map of 'Frontier' and 'Santa Rosa' yields in Ojocaliente, which reveals that a yield gradient would exist in the potential plum-growing area (Fig. 4B). In this district, fruit yields of these two cultivars vary high potential yield area.

According to the GIS analysis and the yield classification (Table 3), plums of the group 'Frontier'-'Santa Rosa' may be recommended in a broader sense because they occupy the largest area (34\%) with the highest yields (up

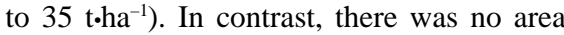
defined in the region where 'Ozark Premier''Burbank' can be cultivated, with expectations of the same high potential yield due to their climatic requirements (particularly winter chilling). However, the method used gives the opportunity of determining the cultivar group or groups that can be cultivated in any particular area and their potential yield. 'Shiro', the most consistent cultivar, had less strict requirements for winter chilling, which suggests that it may be established in a larger area than the two other groups. This suggestion was confirmed by the area analysis with GIS (Table 3 ), which indicated that $\approx 2.5$ million ha in the region might be planted with this plum cultivar; however, because of its relatively low fruit quality and undesirable yellow pigmentation, high market demand for this fruit is not expected. My experimental area is designated as the highlands, with a semi-arid climate, summer rainfall, and scarce winter frosts; however, a classification based on altitude and latitude seems to be more appropriate. The response surfaces generated are applicable to areas between lat. $21^{\circ}$ and $27^{\circ}$ and with an altitude varying from 1900 to $2300 \mathrm{~m}$ above sea level. This area includes several states in the vicinity of Zacatecas, where suitable areas for growing these Japanese plum cultivars can be studied with GIS.

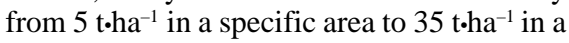

The amount of winter chilling and temperatures during bloom time were the most important climatic conditions related to fruit yield in the included Japanese plum cultivars. 'Frontier'-'Santa Rosa' had lower chilling requirements than 'Ozark Premier'-'Burbank', but 'Shiro', under the experimental conditions, received sufficient chilling in all years. High temperatures at bloom reduced fruit yield in all cultivars. However, the response of yield to temperatures at bloom may be modified by summer temperatures the previous year, suggesting that temperatures at the floral induction and formation stages are important for having strong flowers. Three potential areas for growing plums in the region were defined in maps, and the differences in potential yield between the cultivar groups in the delimited areas were determined. 'Frontier' and 'Santa Rosa' may be good choices as plum cultivars for the region; however, a gradient in potential yield in any specific area was observed, allowing users of GIS the opportunity to select cultivars with expectations of a potential yield range. I suggest that using experimental information and GIS can extend the applicability of data from a germplasm collection to regional planning in orchard establishment.

The relevance of this work relies on the possibility of combining yield-predicting models, using climatic data, and GIS to find the most suitable areas for establishing a fruit crop or cultivar. From the research point of view, it may be useful to introduce new cultivars with similar characteristics and climatic requirements to the cultivars evaluated, having a certain degree of confidence in their adaptation or in the definition of their limitations. The method described also gives the opportunity for broadening the scope of recommendations with regard to genetic material of a particular experimental station. These findings also are important to help fruit growers decide which plant material can be established and to determine its limits of potential yield. In the future, these types of studies should be focused on predicting other aspects of the fruit production system, for example pest and disease occurrences, harvest dates, or irrigation needs for a regional analysis in new developing fruit production areas.

\section{Literature Cited}

Avitia-García,E. and A.M. Castillo-Gonzalez. 1991. Diferenciación floral en Prunus. National Con-

Table 3. Areas, and their percentages with a range of potential yields, for cultivation of three groups of Japanese plum cultivars in Zacatecas, Mexico.

\begin{tabular}{|c|c|c|c|c|c|c|}
\hline \multirow[b]{3}{*}{ Yield $\left(\mathrm{t} \cdot \mathrm{ha}^{-1}\right)$} & \multicolumn{6}{|c|}{ Cultivars } \\
\hline & \multicolumn{2}{|c|}{ Frontier-Santa Rosa } & \multicolumn{2}{|c|}{ Ozark Premier-Burbank } & \multicolumn{2}{|c|}{ Shiro } \\
\hline & Area $^{2}$ & $\%$ & Area $^{2}$ & $\%$ & Area $^{z}$ & $\%$ \\
\hline 0 to 5 & 39.3 & 16 & 53.1 & 27 & 0 & 0 \\
\hline 5 to 15 & 65.3 & 27 & 80.4 & 40 & 0.6 & 0 \\
\hline 15 to 25 & 55.9 & 23 & 64.5 & 33 & 2352.8 & 84 \\
\hline 25 to 35 & 82.2 & 34 & 0 & 0 & 438.2 & 16 \\
\hline Total & 242.7 & 100 & 198.0 & 100 & 2791.6 & 100 \\
\hline
\end{tabular}

${ }^{2}$ Potential area for cultivation in hectares, 1000 s. gress of the Sociedad Mexicana de Ciencias Hortícolas. IV:304. (Abstr.)

del Real-Laborde, J.I. 1987. Estimating chill units at low latitudes. HortScience 22:1227-1231.

Diaz, D.H., J.J. Martinez, and W.B. Sherman. 1986. Apple and peach production in warm climates of Northwest Mexico. Fruit Var. J. 40:121-125.

Erez, A. 1987. Chemical control of budbreak. HortScience 22:1240-1243.

Hilling, K.W. and A. Iezzoni. 1988. Multivariate analysis in a sour cherry germplasm collection. J. Amer. Soc. Hort. Sci. 113:928-934.

Iezzoni, A.F. and M.P. Pritts. 1991. Applications of principal component analysis to horticultural research. HortScience 26:334-338.

Jackson, D.I. and G.B. Sweet. 1972. Flower initiation in temperate woody plants (a review). Hort. Abstr. 42:9-25.

Keulemans, J. 1984. The effect of temperature on pollen tube growth and fruit set on plum trees. Acta Hort. 149:95-101.

La Rue, J.H. and M. Gerdts. 1976. Commercial plum growing in California. Univ. of California. Lflt. 2458.

Lal, H., G. Hoogenboom, J.P. Calixte, J.W. Jones, and F.H. Beinroth. 1993. Using crop simulation models and GIS for regional productivity analysis. Trans. ASAE 40:175-184.

Moreno, Y.M., A.N. Miller-Azarenko, and W. Potts. 1992. Genotype, temperature, and fall-applied ethephon affect plum flower bud development and ovule longevity. J. Amer. Soc. Hort. Sci. 117:14-21.

Perez-Gonzales, S. 1992. Associations among morphological and phenological characters representing apricot germplasm in central Mexico. J. Amer. Soc. Hort. Sci. 117:486-490.

Pimienta, A.E., V.S. Polito, and D.E. Kester. 1983. Pollen tube growth in cross- and self-pollinated 'Nonpareil' almond. J. Amer. Soc. Hort. Sci. 108:643-647.

Richardson, E.A., S.D. Seeley, and D.R. Walker. 1974. A model for estimating the completion of rest for 'Redhaven' and 'Elberta' peach trees. HortScience 9:331-332.

Richardson, E.A., S.D. Seeley, D.R. Walker, J.L. Anderson, and G.L. Ashcroft. 1975. Phenoclimatography of spring peach bud development. HortScience 10:236-237.

Rumayor-Rodríguez, A., G. Medina-García, and T.J. Arellanos-Ledezma. 1991. Efecto de la temperatura en la producción de 12 cultivares de ciruelo. National Congress of the Sociedad Mexicana de Ciencias Hortícolas. IV:74. (Abstr.)

SAS Institute. 1988. SAS/STAT user's guide, release 6.03. SAS Institute, Cary, N.C.

Secretaría de Agricultura y Recursos Hidráulicos. 1993. Determinación del potencial productivo de especies vegetales. Campo Experimental Calera.

Werner, D.J., B.D. Mowrey, and E. Young. 1988. Chilling requirement and post-rest heat accumulation as related to difference in time of bloom between peach and western sand cherry. J. Amer. Soc. Hort. Sci. 113:775-778.

Whistler, F.D., B. Acock, D.N. Baker, R.E. Frue, H.F. Hodges, J.R. Lambert, H.E. Lemmon, J.M. McKinnion, and V.R. Reddy. 1986. Crop simulation models in agronomic systems. Adv. Agron. 40:141-208.

Williams, R.R. 1965. The effect of summer nitrogen applications on the quality of apple blossoms. J. Hort. Sci. 40:31-41.

Williams, R.R. 1970. Factors affecting pollination in fruit trees, p. 193-207. In: L.C. Luckwill and C.V. Cutting (eds.). Physiology of tree crops. Academic, London. 